\title{
New evaluation method to detect physiological stress in fruit trees by airborne hyperspectral image spectroscopy
}

\author{
Tamás, J. \\ Department of Water and Environmental Management, Centre of Agricultural Science, University of Debrecen, \\ Hungary, H-4032 Debrecen, 138 Böszörményi street
}

\begin{abstract}
Summary: Nowadays airborne remote sensing data are increasingly used in precision agriculture. The fast space-time dependent localization of stresses in orchards, which allows for a more efficient application of horticultural technologies, could lead to improved sustainable precise management.

The disadvantage of the near field multi and hyper spectroscopy is the spot sample taking, which can apply independently only for experimental survey in plantations. The traditional satellite images is optionally suitable for precision investigation because of the low spectral and ground resolution on field condition. The presented airborne hyperspectral image spectroscopy reduces above mentioned disadvantages and at the same time provides newer analyzing possibility to the user. In this paper we demonstrate the conditions of data base collection and some informative examination possibility. The estimating of the board band vegetation indices calculated from reflectance is well known in practice of the biomass stress examinations. In this method the N-dimension spectral data cube enables to calculate numerous special narrow band indexes and to evaluate maps.

This paper aims at investigating the applied hyperspectral analysis for fruit tree stress detection. In our study, hyperspectral data were collected by an AISA DUAL hyperspectral image spectroscopy system, with high $(0,5-1,5 \mathrm{~m})$ ground resolution. The research focused on determining of leaves condition in different fruit plantations in the peach orchard near Siófok. Moreover the spectral reflectance analyses could provide more information about plant condition due to changes in the absorption of incident light in the visible and near infrared range of the spectrum.
\end{abstract}

Key words: remote sensing, hyperspectral image spectroscopy, vegetation analysis, precision fruit production

\section{Introduction}

The precision agriculture and the different technological elements of it become general better in the field of the crop production and the animal husbandry all over the world and also in Hungary (Tamás, 2005; Németh et al., 2007). At the same time manly experimental applications were taken place in case of the fruit production in Hungary (Firtha, 2006). The one handicap of the developments is that this precision production system requires spatially correct image/map data to real time control different field technologies. An important point is to fill this gap of developing to apply the effective airborne data acquisition to produce highly accurate ground and spectral resolution data. Airborne Hyperspectral Image Spectroscopy (AHIS) integrates the advantages of more technologies insuring a new complex measuring eventuality. The airborne imaging uses photogrammetric methods, and the spectroscopy is a well known analytical procedure, moreover for the analyst the measuring intensity insures the technical possibilities of image analysis. Hyperspectral images consist of numerous wavebands, each representing a narrow band width of electromagnetic spectrum. In general the spectral reflectance analyses focus on the visible and near- or mid-infrared portions of the spectrum. Hyperspectral imagery provides complete spectra at each pixel location in a scene delivering more information than is possible with a multispectral imaging system having discrete and usually non-contiguous bands (Erives \& Fitzgerald, 2005).
In 2007, the first high-tech AISA DUAL airborne hyperspectral image spectroscopy system (AIS) was installed and operated in cooperation the University of Debrecen, AMTC, Department of Water and Environmental Management with the Hungarian Institute of Agricultural Engineering in Gödöllö-Hungary founded by NKTH. The most important parts of the hyperspectral sensors are the spectrograph, which dissolve the electric waves arrived through the optical rift with the help of prisms and optical screen. The hyperspectral sensor consists of one optic, one spectrograph and one digital cam. The two hyperspectral sensors are mounted and synchronized in a common house, therefore it is known ASIA DUAL system. The two cams can perceive in the visible wavelength, near infrared range and short wave infrared range. Technical information of applied ASIA DUAL hyperspectral system as follows:

- Push-broom hyperspectral imagery sensor with the fibre optic radiation meters (FODIS)

- Miniature integrated GPS/INS sensor, which serves the position, height and momentary situation (pith, roll, yaw) of plane

- Compact PC-based data collector and mobile receiver unit

- CaliGeo software runs as a separate software package under the ENVI software package to do the spectral and geometrical corrections 
The parameters of the hyperspectral image:

- Wavelength: 400-2450 nm (EAGLE: 400-970 nm and HAWK: 970-2450 nm)

- Spectral sample taking: 1,2-10 nm

- Ground resolution: 0,4-3 m (with plane)

The Eagle camera takes images in visible and near infrared range (VNIR), while Hawk operates in the middle infrared range (SWIR). By means of establishing of two camera a DUAL system were installed (Table 1.). The full range 400-2450 $\mathrm{nm}$, which can be set 1,25-10 nm wavelength band and maximum 498 spectral channels. Two sensors can also be operated separately, so it makes possible to utilize the wider wavelength of higher resolution (1024 pixels) VNIR sensor. For first, photogrammetric and spectral accuracies were evaluated by different GPS/Interia system in different flight conditions in Europe (Germany, Finland, Switzerland and Hungary).

In our investigations, the airborne imaging system was used in fruit researches to develop a new GIS based recording system of fruit plantations and study the relationships between remotely-sensed indices and ground control measures of fruit trees.

In our study, the potential of AISA DUAL airborne hyperspectral sensor data to create a narrowband vegetation indexes distribution map of agricultural fields was evaluated.

\section{Materials and methods}

In our investigation site is situated $10 \mathrm{~km}$ south of Lake Balaton, near Siófok ( $46^{\circ} 52^{\prime} \mathrm{N} ; 18^{\circ} 00^{\prime} \mathrm{E}$ ). This plantation consists of parcels of more peach, apricot and nectarine species. The hyperspectral image swath width was $500 \mathrm{~m}$, and the total investigated area was $3,8 \mathrm{~km}^{2}$. The hyperspectral data were collected by an AISA DUAL hyperspectral imaging system, in the wavelength range of $398-973 \mathrm{~nm}$, in 63 channels, with very high $0.5-1 \mathrm{~m}$ ground resolution.

The process flow of the hyperspectral image processing was the following:

1. Aerial and land image taking.

2. Radiometrical and geometrical corrections.

3. Noise filtering and data decrease.

4. Choosing the objective spectrum.

5. Classification.

6. Interpretation.

7. Checking (Burai \& Tamás, 2004).

Steps 1 and 2 were made with the CaliGeo (radiometric and geometric corrections), while for steps 3 to 6, ENVI 4.6 raster based hyperspectral remote sensing software and 7th in ESRI ArcGIS 9.3 GIS environment were applied. The objectives of calibrating remote sensing data are to remove the effects of the atmosphere (scattering and absorption) and to convert radiance values received at the sensor to reflectance values of the land surface.

On the bases of flight altitude 500-1000 m swath width can reach with $40-60 \%$ image overlap. If the average speed of the flight is $250-300 \mathrm{~km} / \mathrm{h}$, so that in case of one flight strip 200-250 $\mathrm{km}^{2}$ airborne image can be created, which means 25-40 terabytes information. The critical point of data spatial correction is the collecting 3 dimension reference points with high-speed GPS.

Table 1. Technical specification of AISA DUAL hyperspectral camera

\begin{tabular}{|c|c|c|c|c|c|}
\hline Specification & \multicolumn{4}{|c|}{ VNIR (EAGLE) } & SWIR (HAWK) \\
\hline \multicolumn{6}{|c|}{ Sensors characteristics } \\
\hline Spectral range & \multicolumn{4}{|c|}{$400-970 \mathrm{~nm}$} & $970-2450 \mathrm{~nm}$ \\
\hline Spectral resolution & \multicolumn{4}{|c|}{$2.9 \mathrm{~nm}$} & $8.5 \mathrm{~nm}$ \\
\hline Spectral binning options & none & $2 \times$ & $4 \times$ & $8 \times$ & none \\
\hline Spectral sampling & $1.25 \mathrm{~nm}$ & $2.5 \mathrm{~nm}$ & $5 \mathrm{~nm}$ & $10 \mathrm{~nm}$ & $6 \mathrm{~nm}$ \\
\hline \multicolumn{6}{|c|}{ Fore optics } \\
\hline \#spatial pixels & \multicolumn{2}{|c|}{320} & \multicolumn{2}{|c|}{1024} & 320 \\
\hline FOV & \multicolumn{2}{|c|}{24} & \multicolumn{2}{|c|}{37,7} & 24 \\
\hline IFOV & \multicolumn{2}{|c|}{0.075 degrees } & \multicolumn{2}{|c|}{0.075 degrees } & 0.075 degrees \\
\hline Swath with & \multicolumn{2}{|c|}{$0.65 \times$ altitude } & \multicolumn{2}{|c|}{$0.65 \times$ altitude } & $0.39 \times$ altitude \\
\hline \multicolumn{6}{|c|}{ Electrical characteristics } \\
\hline Radiometric resolution & \multicolumn{4}{|c|}{12 bits (CCD) } & 14 bits (MCT) \\
\hline SNR & \multicolumn{4}{|c|}{$350: 1$ (peak) } & $800: 1$ (peak) \\
\hline Image rate & \multicolumn{5}{|c|}{ Up to 100images/s } \\
\hline
\end{tabular}

The C-MIGITS III and OxTS - RT 3003 GPS/INS systems were applied for collecting navigation data for direct geometric correction. External DGPS data were used for controlling the GPS/INS system. Several images were taken to monitor the direct georeferencing of push-broom scanner data with or without external DGPS using ground control points (GCP's). OxTS - RT 3003 was showed pixel sized accuracy of $1 \mathrm{~m}$ without external DGPS data while the CMIGITS III provided about $6 \mathrm{~m}$ RMS position error, when the average flight altitude was $800-1000 \mathrm{~m}$ and the average speed was $200-250 \mathrm{~km} / \mathrm{h}$, with minimum swath width of $500 \mathrm{~m}$

In the reference point, leaf sample were collected from top young part of fruit tree and mid-lover part as suggested by a Hungarian agro-chemistry reference book. The chlorophyll A contents of leaf were measured according to the ISO 10260:1993 patent, using hot ethanol (90\%) for the extraction. The chlorophyll A absorbance was detected by Anthelie UVVIS spectrophotometer at $665 \mathrm{~nm}$ and $750 \mathrm{~nm}$ wavelengths.

The reflectance spectra of leaf and fruits were measured by a field portable, ALTA II type spectrometer at 470, 525, 560, 585, 600, 645, 700, 735, 810, 880, and $940 \mathrm{~nm}$. Leaf area of fruit trees was measured by ADC AM 100 typed leaf are scanner, continuously tracking the flight campaign, to get information about the transpiration surface, which is important for the determination of the amount of daily transpiration (Tamás \& Nagy, 2004).

Our data base also contained topographic maps, truecolor airborne images and field surveys data, and supporting data about fruit tree sub-species. For the characterisation of the soil the most important soil parameters were determined at every study area. 

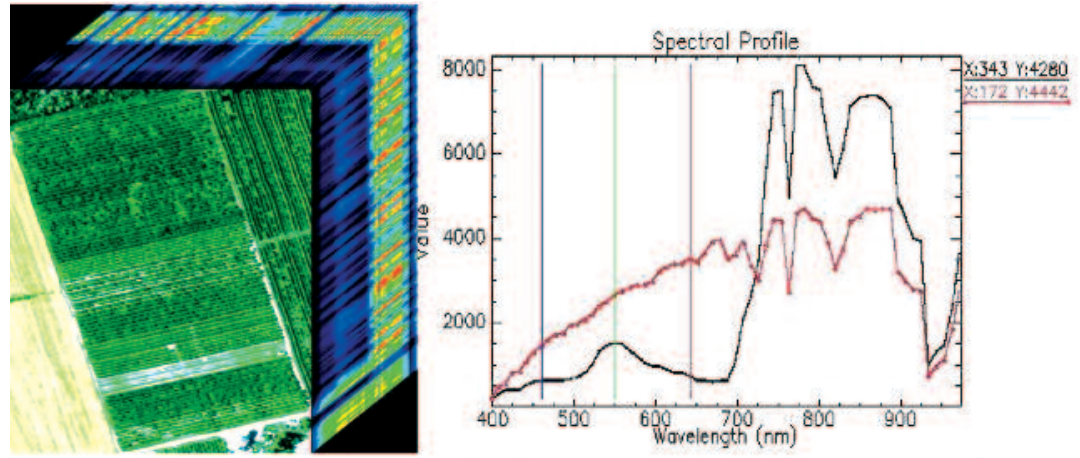

Figure 1: The 3D data cube made from 69 VIS-NIR channels and spectral reflectance curves of pixels, in Siófok

\section{Results and discussion}

Photosynthetically active leaf pigments affect only the visible portion of the shortwave spectrum (400nm to $700 \mathrm{~nm}$ ), though the effect depends on the type of pigment; this is the main reason why VNIR range is especially important for vegetation analysis. At the time of data acquisition, the calibration site was also characterized with a field spectrometer, which is very important (Clark et al., 2002).

After the geometric and radiometric correction the hyperspectral $\mathrm{N}$-dimensional data cube was made, which was ready for classification. This data cube contains all geographical and spectral data changing pixel by pixel (Figure 1).

On the right side of the Figure 1. the spectral curves of the two neighbouring area is represented in geographical accurately. The reflectance differentiates from the lower soil values particularly between $600-720 \mathrm{~nm}$ in the red edge spectral range.

Before classifications, spectrally clean, not mixed pixels of the objects should be identifying. These are the spectrally not correlated pixels called spectrally endmembers that are spectrally matched to similar spectral curves in the spectral space. In Figure 1, right site presents two typical endmembers, one of them is a green biomass of peach tree canopy in $343 \mathrm{x}, 4280 \mathrm{y}$; while, the left side shows a spare meadow type physically light clay soil in 172 $\mathrm{x}, 4442$ y pixel position. The curves show relatively high differences in red channels around $650 \mathrm{~nm}$ and NIR channels close to 740 $\mathrm{nm}$, and this is why these ranges are intensively used for interpretations.

The leaf area index (LAI) is the green leaf area per unit ground area, which represents the total amount of green vegetation present in the canopy. The LAI is an important property of vegetation, and has the strongest effect on overall canopy reflectance resulted from leaf pigment activities. Our results are confirmed by Jung and Tökei's data measured by DAIS sensor in course of HYSENS project (2005). The calculated Pearson correlation between LAI and NDVI values was strong positive Siófok
$(0.8-0.9)$. LAIs of peach tree were between $3-8$, in the $1^{\text {st }}$ week of June. The trees with higher LAI value presented higher means values and standard deviation in the NIR range as the visible range (Figure 2).

Before the spectral analysis a mask was used to choose the green biomass area in the investigation field on the basis of the histogram of the NDVI index map. Segmentation of NDVI image was the following: no vegetation $(\leq 0.3)$, sparse vegetation $(0.3-0.7)$, moderate vegetation $(0.7-0.82)$, dense vegetation $(\geq 0.82)$.

To reduce dimensionality and compress the real information about spectral endmembers, the Minimum Noise Fraction -cascade analyses and Pixel Purity methods were applied based on Green et al. (1988), and Boardman and Kruse (1994). The spectral curves of endmembers show the spectral values of each object in every band without auto correction, which are bases of the SAM classification. Spectral Angle Mapper (SAM) is a physicallybased spectral classification that uses an n-D angle to match pixels to reference spectra. The algorithm determines the spectral similarity between two spectra by calculating the angle between the spectra and treating them as vectors in a space with dimensionality equal to the number of bands.

The following classes were sampled in the spectral study area, between brackets the number of the examined pixel and the value of the spatial accuracy were indicated: Spare vegetation (7011-83\%); Dry grass (1386-79.4\%); Green grass (6257-68.2\%); Weed (7659-72.3\%); Yellow canopy (8480-89.6\%), Stressed canopy (9142-69.7\%) Green canopy (24683 92.4\%) Greenest canopy (15890 95.2\%).

The characteristics of the reflectance curves of each fruit tree species result from the large amount of absorption of chlorophyll A content at 450-670 nm wavelength intervals. On the other hand, reaching the near infra-red (NIR) interval, the reflectance of the healthy fruit tree leaves are raising markedly at $700 \mathrm{~nm}$. Besides, the reflectance value of the vegetation without any stress is high at NIR intervals, but low

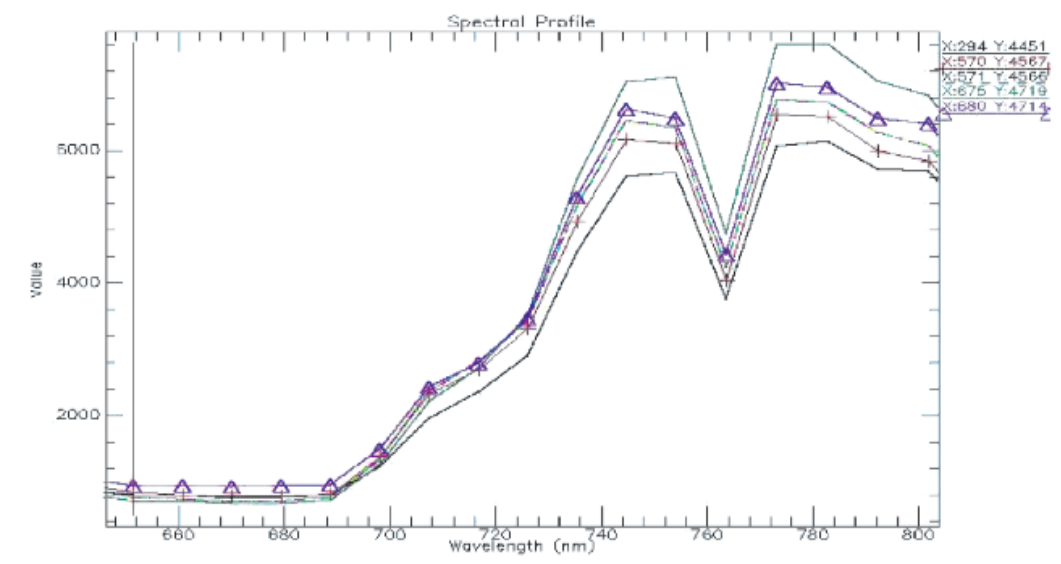

Figure 2: Increasing LAIs of peach tree give higher reflectance values in $740-800 \mathrm{~nm}$ range, in 
at red wavelength interval. The chlorophyll content is one of the indicators of the state of health before ripening phonological phase. The biomass samples taken in the study area were collected and analyzed on the basis of spectral class. Around fruit tree the $\mu \mathrm{g} / \mathrm{g}$ mean and standard deviation of the average chlorophyll values are as follows: Dry grass (512, 190); Spare vegetation $(1285,549)$; Weed $(975,298)$; Green grass $(1117,210)$, Yellow grass $(674,261)$. The $\mu \mathrm{g} / \mathrm{g}$ mean and standard deviation of the average chlorophyll values of foliage of fruit tree are follows: Stressed canopy (1072 340), Yellow canopy $(814,496)$, Green canopy (1302, 231), Greenest canopy (1689, 272).

The Red Edge Normalized Difference Vegetation Index $\left(\mathrm{NDVI}_{705}\right)$ is intended for use with very high spectral resolution reflectance data. Applications include precision agriculture (an information- and technology-based agricultural management system to identify, analyze, and manage site-soil spatial and temporal variability), forest monitoring, and vegetation stress detection (Gitelson et al., 1994). This VI differs from the NDVI by using bands along the red edge, instead of the main absorption and reflectance peaks. The NDVI 705 capitalizes on the sensitivity of the vegetation red edge to small changes in canopy foliage content, gap fraction, and senescence. The value of this index ranges from -1 to 1 . The common range for green vegetation is 0.2 to 0.9 (Smith et al., 2004).

\section{Conclusion}

In 2007, one airborne hyperspectral image analysis research service, which is high tech in the Europe relation, was installed in Hungary. The high spectral and ground resolution AISA DUAL cameras collect continuously spectral data pixel by pixel. The spectral reflectance analyses could provide very detailed real time, mapable information about plant condition due to changes in the absorption of incident light in the visible and near-infrared range of the spectrum. Based on $\mathrm{N}$-dimensional image analysis can calculate more accurate narrow band vegetation indexes than traditional satellite data sources. Next future these methods effectively can help to intensify precision fruit production.

\section{Acknowledgement}

The author thanks László Fenyvesi, József Nyéki, Prof. Zoltán Szabó, Csaba Lénárt, Péter Burai and Tünde Fórián for insuring of the data base and the professional advices. This research work was funded by NKTH GYUM2008; BIODEB08; KLIMA09 projects.

\section{References}

Burai, P. \& Tamás, J. (2004): Hyper- and multispectral remote sensing technologies in precision agricultural water management, III. Alps-Adria Scientific Workshop, Dubrovnik, Croatia, pp. 54-57.

Clark, R.N., King, T.V.V, Klejwa, M., Swayze, G., \& Vergo, N. (1990): High Spectral Resolution Reflectance Spectroscopy of Minerals, J. Geophys Res., 95: 12653-12680.

Clark, R.N., Swayze, G.A., Livo, K.E., Kokaly, R.F., King, T.V.V., Dalton, J.B., Vance, J.S., Rockwell, B.W., Hoefen, T., \& McDougal, R. R. (2002): Surface Reflectance Calibration of Terrestrial Imaging Spectroscopy Data: a Tutorial Using AVIRIS, "10th Airborne Earth Science Workshop", JPL Publication 2: 1.

Erives, H. \& Fitzgerald, G.J. (2005): Automated registration of hyperspectral images for precision agriculture. Computers and Electrics in Agriculture, 47: 103-119.

Firtha, F. (2006): Controlling and calibration of hyper-spectral measurement, Journal of Food Physics, Budapest, Vol. 17-18: $13-28$.

Gitelson, A.A. \& Merzlyak, M.N. (1994): Spectral Reflectance Changes Associated with Autumn Senescence of Aesculus Hippocastanum L. and Acer Platanoides L. Leaves, Spectral Features and Relation to Chlorophyll Estimation, Journal of Plant Physiology, 143: 286-292.

Green, A. A., Berman, M., Switzer, P. \& Craig, M. D. (1988): A transformation for ordering multispectral data in terms of image quality with implications for noise removal, IEEE Transactions on Geoscience and Remote Sensing, 26 (1): 65-74.

Kardeván, P., Vekerdy, L., Róth, L., Sommer, S., Kemper, T., Jordán, Gy., Tamás, J., Pechman, I., Kovács, E., Hargitai, H. \& László, F. (2002): Outline of scientific aims and data processing status of the first Hungarian hyperspectral data acquisition flight campaign, HYSENS 2002 HUNGARY, "3rd EARSEL Workshop on Imaging Spectroscopy”, 13-16 May, Herrsching, Germany, pp. 324-332.

Jung, A., Tökei, L. (2005): Detection of urban effect on vegetation in a less build-up Hungarian city by hyperspectral remote sensing. Physics and Chemistry of the Earth, 30: 255-259.

Németh, T., Neményi, M. \& Harnos, Zs. (2007): Methodology of Precision Agriculture (in Hungarian) JATE Press., 1-238.

Smith, K.L., Steven, M.D. \& Colls, J.J. (2004): Use of hyperspectral derivative ratios in the red-edge region to identify plant stress responses to gas leaks, Remote Sensing of Environment, 92: 207-217.

Tamás, J., (2001): Precision agriculture (in Hungarian), Szaktudás Kiadó, Budapest, pp.1-160.

Tamás, J. (2007): Environmental Informatics in Agri-environmental Management (in Hungarian), Szaktudás Kiadó, Budapest, 1-162.

Tamás, J. \& Nagy, A. (2009): Canopy analysis of peach tree by hyperspectral image analysis (in Hungarian), Csete, L. (ed.) Klíma 21. (58): 36-45. 